\title{
Using Old Concepts to Gain New Insights: Addressing the Issue of Consistency
}

\author{
(Colin Jones) \\ University of Tasmania \\ Faculty of Business \\ Private Bag 16 \\ Hobart TAS 7001 Australia \\ Phone: +61 362262826 \\ Fax: +61 362262808 \\ Email: Colin.Jones@utas.edu.au
}

\begin{abstract}
Purpose of the paper: This paper aims to go beyond a bookkeeping approach to evolutionary analysis whereby surviving firms are better adapted and extinct firms were less adapted. From discussion of the preliminary findings of research into the Hobart pizza industry, evidence is presented of the need to adopt a more traditional approach to applying evolutionary theories with organizational research.
\end{abstract}

Methodology/Approach: After a brief review of the relevant literature, the preliminary findings of research into the Hobart pizza industry are presented. Then, several evolutionary concepts that are common place in ecological research are introduced to help explain the emergent findings. The paper concludes with consideration given too advancing a more consistent approach to employing evolutionary theories within organizational research.

Findings: The process of selection can not be assumed to occur evenly across time and/or space. Within geographically small markets different forms of selection operate in different ways and degrees requiring the use of more traditional evolutionary theories to highlight the causal process associated with population change.

Research Implications: The paper concludes by highlighting Geoffery Hodgson's Principle of Consistency. It is demonstrated that a failure to truly understand how and why theory is used in one domain will likely result in its misuse in another domain. That at present, too few evolutionary concepts are employed in organisational research too ensure an appreciation of any underlying causal processes through which social change occurs.

What is the original/value of paper: The concepts introduced throughout this paper, whilst not new, provide new entry points for organizational researchers intent of employing an evolutionary approach to understand the process of social change.

Keywords: Selection, Adaptation, Selective Environmental Neighbourhoods and the Principle of Consistency 
Paper type: Case Study

\section{Introduction}

Too often firms are assumed capable of adaptive change, or conversely, assumed incapable of adaptive change. An emerging school of thought based on a contingent approach that simultaneously entertains both notions increasingly commands more attention. This middle ground belongs to those pragmatic researchers who seek to understand the interrelated process of selection and adaptation (e.g. Levinthal, 1991; Haveman, 1992; Amburgey, Kelly, and Barnett, 1993; Bruderer and Singh, 1996). This paper presents preliminary evidence gained from the Hobart pizza industry to propose that the assumed dialogic relationship (between selection and adaptation) is even more difficult to explain than typically portrayed.

Through the use of an evolutionary approach, it argued that additional layers of analysis await those who truly wish to appreciate the underlying processes of adaptation and selection occurring within dynamic and changing social systems. In presenting this argument, it is acknowledged that the use of evolutionary theory within the fields of economics, organisational studies, and to a lesser degree, sociology is less developed than that of biology and ecology. The central claim of this paper is that this difference in depth of application restricts a full understanding of what actual processes surround the process of survival and extinction in the social domain. That, without the willingness to adopt a multi-disciplinary approach and observe the principle of consistency (Hodgson, 2001), the eventual value of much research in this area will be reduced.

The remainder of the papers is structured as follows. First, a general outline of the research area and the method employed to collect the data thus far will be presented. Second, the events of the Hobart pizza industry will be discussed. Third, the implications of the preliminary case findings will be considered, before the paper concludes with a summary of the key findings to have emerged so far.

\section{Adaptation and selection}

That firms are expected to be capable of adjusting their interacting elements to achieve better fit is a claim that is as equally supported (e.g. Tushman and Romanelli, 1985; Levitt and March, 1988) as refuted (e.g. Hannan and Freeman, 1989). However, increasingly this area of discussion is less about a dichotomy of opinion, and more about questions of how the processes of selection and adaptation interrelate (e.g. Levinthal, 1991). The emergence of a contingent view of change occurring within populations (or industries) rests largely on the assumption that selection and adaptation are constant dance partners. That across differing conditions, either the process of selection or adaptation may be more dominant (Amburgey and Singh, 2002). So, two interrelated processes of differing and alternating strength.

Selection that produces evolution has been defined "as repeated cycles of replication, variation, and environmental interaction so structured that 
environmental interaction causes replication to be differential" (Hull, Langman and Glenn, 2001, p. 53). Within organizational studies, selection is typically thought of as external forces or forces within a firm "that differentially select or selectively eliminate certain types of variations" (Aldrich, 1999, p. 26). It is quite often assumed such forces ensure conformity to instutionalized norms and adherence to past (internal) selection criteria. However, as will be explained shortly, other forms of selection are possible.

In line with the selectionist and adaptationist views of population change, adaptation can be seen to occur at two separate levels. From the selectionist perspective, the types of routines and competencies that provide the best fit with the prevailing environment will be selected in favour of. Through this process, the frequency of certain types of routines and competencies within a population is determined seemingly by the randomness of external selection pressure. Alternatively, firms can determine their own destiny through altering (or maintaining) their routines and competencies in order to achieve a better fit with their environment.

Essentially, the selectionist approach is seen as Darwinian, the ordering activity of the environment (natural selection) is preceded by variation within a population. The outcome will be the "preservation of favourable variations and the rejection of injurious variation" (Darwin, 1901, p. 58). Alternatively, the adaptationist approach is commonly thought to be Lamarckian in nature, with variation a function of the environment (Hodgson, 1993) and acceptance of "both the inheritance of acquired characteristics and the timely appearances of variation under the stimulus of adversity" (Nelson and Winter, 1982, p. 11). Importantly, Lamarckism does not assume beneficial progress, given that acquired characteristics could prove to be either beneficial or detrimental.

In summary, the remainder of the paper is devoted to the discussion of the preliminary observations that have emerged from the ongoing study of the Hobart pizza industry. To date, the research has proceeded on the basis of combining the data received from unstructured interviews and analysis of archival phone listing records. This approach has enabled both accurate and codable data to be used in conjunction with data representative of the views of the operators across the life course of the industry. The phone listing records in particular offer valuable insights (Evans and Usher, 1996) into the gaols, boundaries and activities of each firm over time. They provide access to a snapshot of what was being offered for consumption vis-à-vis other competitors and the nature of the operating environment. Issues arising from these preliminary findings will be explored during the conclusion by way of inviting further investigation of specific issues that challenge the conventional wisdom discussed briefly above.

\section{The Hobart pizza industry}

The Hobart pizza industry grew from the humble, yet passionate aspirations of a few Italian post-war immigrants. Since 1969, the few restaurants that comprised the industry were frequented mainly by Italians. During the past 37 years, more than 115 firms have contested the market, with around 38 open 
for business today. The industry has been the playground of many irrepressible entrepreneurs, the burial ground for many an honest operator, and the battle ground for various franchised operations. The story of the Hobart pizza industry is essentially one that relates to the constant interaction between those early pioneers, those that followed, and those that entered the market with national or global operations already in existent.

The industry's history can be divided into three distinct periods. The first period $(1969-1983)$ covered the years before the entry of the first franchised operator. The second period (1984 - 1994) was post the first franchised entrant, but prior to the entry of the second franchise operation. The third period (1995 - to present) relates to the period after the entry of the second franchise operation to present. The following discussion will reveal the significance of the period effects noted in Figure 1 below.

Figure 1 - The Hobart pizza industry 1969 - 2004

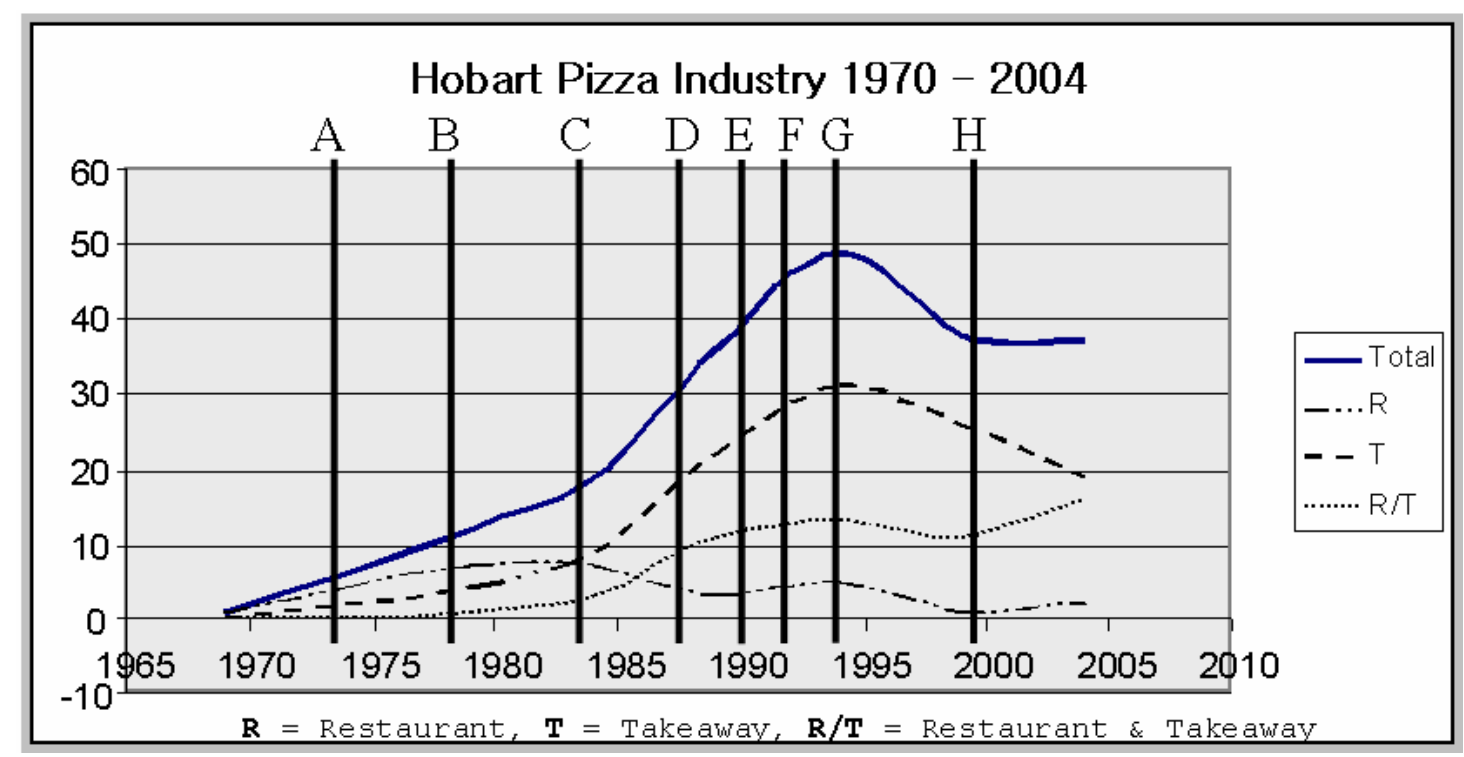

\section{Period effect legend}

$A=$ Opening of Wrest Point casino

$\mathrm{B}=$ Introduction of the 1976 liquor act

$\mathrm{C}=$ Introduction of first franchise operator \& random breath testing

$\mathrm{D}=$ The beginning of home delivery

$\mathrm{E}=$ The 1990 recession

$F=$ The introduction of conveyor belt ovens

$G=$ The introduction of second franchise operator

$\mathrm{H}=$ The introduction of the GST

In general, the industry has been transformed from low volumes and high margins to one that now has high volumes and low margins. The many social trends that have accompanied the industry's growth are perhaps best considered throughout the following discussion of each distinct period. 


\section{Period One - 1970 to 1982}

Like many Australian cities, Hobart was positively impacted upon by the multicultural influence of the many post-war migrants who made Australia their new home. The pizza industry was one such development, complete with its own sense of theatre (e.g. the tossing of the dough). However, the primary market of the few restaurants in the early 1970s was soccer clubs and other social groups intimately tied to the Italian community. The nature of consumer demand for pizza was radically altered by two events in the 1970s. The first in 1974 being the opening of Australia's first legal casino in Hobart. The second in 1977 being the changing of the local Licensing Act to allow patrons to frequent hotels and bars beyond 10pm.

The effect of these two interrelated events was very significant. Firstly, the Casino created after hours demand for food, for which at that time the only establishments open late were pizza shops. Following the protests from hoteliers that the Casino had an unfair advantage (i.e. a virtual monopoly for entertainment after 10pm), the relaxing of general opening hours for all hotels and bars turned the Casino's trickle of customers into a flood of hungry patrons. Many more Italians entered the industry to take advantage of the good times. Whilst many of the new operators had little knowledge of how to make a pizza, the social networks common to them all ensured the transfer of knowledge. This transfer of knowledge also frequently occurred at the Casino where many of the pizza shop owners would meet to 'brag' and swap stories and information related to their individual operations. Given the even distribution of their operations throughout Hobart, little competition existed amongst the pioneers, who at this stage struggled to keep up with demand, in what was still a high margin industry.

\section{Period Two - 1983 to 1993}

The next major event in the industry was the arrival of the first franchise operator (F1). Far from being viewed negatively, F1's presence appears to have benefited incumbents in a number of specific ways. First, it substantially increased the primary demand for pizza. Second the marketing methods used by F1 to stimulate primary demand were quite visible and relatively easy to copy by the incumbents. Finally, F1's presence led to a change in the time that pizza was consumed. Pizza became not solely the domain of the drunken and partied, it moved back towards those about to party, those thinking about dinner or even lunch. By altering the hours during which pizza was consumed, many pioneers were encouraged to remain in the industry. The need to be 'on deck' when production was peaking, typically after 10pm, had eased. Owners could now work restaurant hours, returning to a more normal life through having a manager in charge to finish the late shift.

The future of the industry was then reshaped by the entry on of a new innovative entrant who introduced the mainland practice of home delivery to Hobart. This further stimulated demand and was associated with increasing new entrants. Throughout this period the positive influence of F1 on the industry continued. As they ran television advertisements, it acted to increase demand at many local pizzerias. What emerged were two specific consumers, 
those that stayed loyal to their perceptions of quality, and those that were more price conscious. With around 26 firms operating in the industry, there were calls for government regulation from those incumbents who felt the market was nearing saturation.

Home delivery was a huge success, occurring at a time when drink driving was increasingly frowned upon. By 1990, Australia was in the grip of a severe recession that proved beneficial for the pizza industry. A combination of not being perceived as a luxury good and the downward pressure on pizza prices resulted in pizza being categorised as a normal good with elevated status during hard times. It was also a time of unbridled experimentation and innovation. Many operators increased their efficiency to counteract the decreasing margins caused by increasing competition, installing computerised systems and purchasing new equipment. The conveyor belt oven was one such innovation that gained a foothold. However, despite its ability to smooth production, improve quality, and reduce employee injuries (e.g. burns), its use was not positive for all. For some, the conveyor belt oven provided the opportunity to use less skilled labour, potentially threatening the levels of service and quality in other aspects of the business. By 1993, around 50 firms were operating in the Hobart pizza industry.

\section{Period Three - 1994 to present}

The arrival of the second franchise operator (F2) in 1994 radically changed the nature of the industry. The past focus on promoting pizza in general gave way to increased price competition. The population size fell rapidly (17 exits over three years) as F2 adopted a 'fastest gun in the west' approach to pricing. This was further reinforced with the arrival of the third franchise operator (F3) in 1996. Three factors in particular seemed to greatly influence who stay and who left. Firms that were unable to maintain prerequisite levels of great food, service, and ambience were in the direct line of fire. Market forces that had apparently lay dormant for many years all of a sudden selected against them. It would seem that while many firms had adapted to an operating environment using a quality baseline, other firms unable to deliver (or develop in time) these three success factors and were susceptible to competing upon a price dependent (cost) baseline.

While pizza had been elevated from a meal fit for the court jester to one fit for royalty, both customer types still remained. While the court jester's needs could be satisfied by the likes of F1, F2, and F3, it required an entirely different type of business model to compete within the quality end of the market. The middle ground was the most dangerous path travelled. If the time period that covers the two years prior and after F2's entry (1992 to 1996) is considered, it is clear that survival was a tough assignment for new entrants. Of the 23 start-ups during this time period, only 5 survived to the present. The survivors are all linked by previous industry experience, good locations (especially regionally based shops), and a focus on quality. Quality is still the main driver, as is innovation. One particular local entrepreneur, Mario, was one of the first operators to fully exploit the takeaway nature of the industry when he opened his Pizza Palace in 1977. He was the first local operator to 
exploit the demand for home delivered pizza, and has opened many outlets throughout southern Tasmania. He now sells pizza by the slice, targeting an entirely different target market.

The last significant change in the operating environment was the introduction of a Goods and Service Tax (GST) in 2000 by the Australian Federal Government. It is unclear to what degree this caused problems to existing operators given that well-established operators have continued through its introduction until the present. However, it seems that a combination of traits related to poor financial management and poor positioning were selected against. For the franchised operators, their market segments are contested through continual product innovation and pricing strategies. At the other end of the market, the passionate pursuit of quality, service, and ambience remain the keys to success. The middle ground remains for the wily operators to traverse; getting it right in the middle is not as easy as it was when the market was booming in the late 70 s and 80 s. Those that have survived the past 30 years in this industry have done so through an ability to exploit their own strengths and find a way through a maze of different organisational forms and production and marketing processes.

In summary, during the past 37 years a series of period effects (Aldrich, 1999) have both positively and negatively shaped the nature of the industry. At times, selection forces appear to have been operating in different ways, and even sometimes appearing to have been almost non-existent. Further, it would seem that F1 has provided some form of protection to the local independents operators, whereas F2 and F3 have behaved in a predatory manner.

\section{Discussion}

At first glance the events of the past 37 years in the Hobart pizza industry may appear normal. However, as will be argued, several factors when focused upon stretch the applicableness of current evolutionary theories employed in organisational studies for a cogent explanation. Levinthal (1991), in uniting the adaptationist and selectionist views argues that it is the interrelatedness of both processes that is of most importance. Essentially, in accepting Levinthal's argument, we would therefore assume the continuous presence (to some degree) of both forces. That is, that those firms that wander too far from optimal fitness would be selected against. Also, during times of change, many firms would be capable of altering their elements of interaction to maintain or improve fitness. However, when the nature of selection is considered, it can be observed that between 1970 and 1987 there wasn't any noticeable selection pressure. As such it would have been difficult for many firms to sense and feel what types of internal change were required to maintain or increase fitness.

The problem this creates is that without environmental selection occurring, evolution cannot occur by means of natural selection (Brandon, 1990). For evolution, we must have variation occurring in a population, some process of ensuring the retention of favourable practices, and a means of sorting the 
relative fitness of firms in the relevant industry. Also, we assume that this process is characterised by a scarcity of resources, that there is some form of competition between the members of the population. To explore an alternative evolutionary explanation of what has occurred in the Hobart pizza industry, the following syllogism will be used to guide the forthcoming discussion:

- It is possible that change can occur within a population of firms without the direct pressure of natural selection. That is, (natural) selection may be limited in time and space and temporally disconnected from firm level variation, therefore,

- It cannot always be assumed that change in a firm's interacting elements is due to interrelated processes of adaptation and (natural) selection. As a result, the relative degree of fitness ascribed to firm level variations may also be difficult to determine, therefore,

- Any evolutionary approach used to explain the development of an industry must also be capable of explaining the apparent absence of (natural) selection across time and space whilst also accounting for continuous variation at the firm and population level.

The above syllogism assumes that the environment is not merely one external force that casts a long and wide shadow. What is being considered is the uneven distribution of selection pressures across a population of firms. Think of the shadows cast on a partly cloudy day. While some areas remain in sunshine, other areas may be covered in shadow or even precipitation. So, the nature of this argument is that the impact of natural selection within an industry may not be even despite the apparent sameness of the general environment. Further, that factors outside the control of the firms may fix the boundaries and intensity of the selection space. Before considering how these ideas may relate to the Hobart pizza industry, let us first introduce and explain some concepts that would seem new to the field of organizational research.

In the fields of biology and ecology it is now common to distinguish between three forms of environment. Brandon (1990) identifies these forms as the external, ecological, and selective environments. He states the need to determine the degrees of heterogeneity across time and space with regards selection pressure. That is, to determine to what extent firms of similar type experience different survival prospects based on factors beyond their control? Before explaining these concepts further, two more concepts will be introduced to enable the forthcoming discussion to develop more smoothly.

It has long been recognised that natural selection while "the most important is means of modification, it is not the only form of selection occurring" (Darwin, 1901, p. 4). Other forms of selection interact and influence the degree of force associated with natural selection. We can of course intervene to artificially select for particular traits (e.g. market regulation) and to learn from experience and retain behaviours on the basis of their superior consequences. Simply 
called internal selection by Aldrich (1999), this paper will not be sidetracked by the complexity of a closely related debate (i.e. the Darwinian-Lamarckian divide) that is well cover by others (e.g. Hodgson, 2001). That debate can be sidestepped with reference to the term operant selection. Operant selection (Hull, 2001) is the deliberate retention of behaviours that (as a result of chance, experimentation or intentionality) prove beneficial. It is widely acknowledged that operant behaviour is determined by operant learning and this affects the operant repertoire (i.e. people, technologies, products, and image) through which firm interaction (Jones, 2005) with its environment occurs.

Putting aside the issue of artificial selection (as there has been no market regulation of the Hobart pizza industry), one other form of selection is worthy of introduction. The process of natural selection can be negatively or positively influenced by kin selection. Kin selection relates to (intentional or unintentional) behaviours by one actor towards another, that while beneficial to the recipient, may be at least potentially harmful to the actor (Mayr, 1997). It would seem that such selection has occurred during three occasions. Firstly, the initial pioneers engaged in a process of competitive bragging at the casino during which they disclosed valuable information to competitors and their employees. Secondly, the impact of F1 was to increase primary demand of pizza for all industry participants. Lastly, the arrival of F2 and F3 has seen all franchised operators continue to transfer demand (via their television advertising) to all regional operators and to a lesser degree to many suburban operators.

Now we can return to the issue of different forms of environment and consider an alternative explanation of evolutionary change within the Hobart pizza industry. In working towards this alternative explanation, it is the intention to go beyond a book keeping approach through which post hoc deductions are drawn from observation of which firms have survived and which are extinct. The strategic intention of the paper is to shine some light on the causal processes of adaptation and selection. Essentially, in order to attach explanatory and predictive value to the process of natural selection, we must factor in other forms of selection, and also determine the nature of the environment the firms operate within.

\section{Types of environment}

Typically, selection is seen to occur through the interaction of an entity and its environment. However, as discussed, the concept of environment in other fields (Brandon, 1990) is now seen as being more than one general force. The external environment typically refers to the sum total of all factors external to the firm that influence its survival. However, this view of environment does little to highlight which factors are of most importance to one firm or another. It essentially relates to the factors that all firms in all industries are exposed to (e.g. high interest rates).

The environment that Brandon (1990) identifies as the ecological environment refers to a narrowing down of focus. Now we are only concerned with those 
factors that specifically affect a firm's ability to contribute to the growth of its industry (e.g. the increasing availability of resources). The last form of environment is the selective environment. The selective environment refers to those factors of the external environment that specifically determine the differential fitness of the firm's interacting elements (i.e. consumer taste).

A key point is that selection can occur across time and in space differentially. As identified by Grant (1985) and noted by Amburgey, Dacin \& Kelly (1994) and Jones (2005) the characteristics of the process of selection can also differ quite markedly. The process of natural selection can be considered in three general patterns, stabilizing, directional, and disruptive. Stabilizing selection (e.g. the reduction of variance) equates to the most common interpretation of selection through which specific outer lying traits are selected against. Disruptive selection (e.g. removal of some firms from the population's extreme interior distribution along some dimension to form a new population) is the most invasive form of selection. Finally, directional selection (e.g. movement of the mean of a population along some dimension) is common during times of sustained (but predicable) change. Finally, the last concept to be considered is that of selective environmental neighbourhoods (Brandon, 1990).

This useful concept allows us to factor in the differential relative fitness (across time and space) of apparently similar firms within a population. Returning to the dance hall analogy, we can beyond assuming that all dance halls will feature constant dance partners, to now also consider that many of the dance halls will cater to different consumers and play different music. Accepting that this may be the case means that we acknowledge the presence of heterogeneity throughout an industry's time and space. So lets gather our thoughts.

The environment can be broken into different forms, the external, ecological and selective. The ecological environment contains those factors that influence potential growth and the selective environment relates to those factors specifically associated with differential selection. The nature of selective pressure can have a disruptive, stabilizing, or directional influence on the composition of the industry. There are unequal degrees of selection pressure spread across time and space that relate specifically to identifiable neighbourhoods within which similar types of firms will not be selected for or against equally. Lastly, this process of interaction between the firm and its selective environment can be influenced positively or negatively by the presence of kin selection.

Clearly, this is a more involved process of selection than typically outlined in many post hoc deductive evaluations of how industries change. It is the properties of the environment that sort out which firms have differential success. So, and importantly, firms of varying perceived fitness may have potentially equal realised fitness dependent upon the degree of environmental heterogeneity. Returning to the Hobart pizza industry, we can use a series of illustrations to help clarify the application of the abovementioned concepts. 
Figure 2 provides an illustration of how selection has favoured different neighbourhoods across time and space in the Hobart pizza industry.

Figure 2 - Different selective neighbourhoods

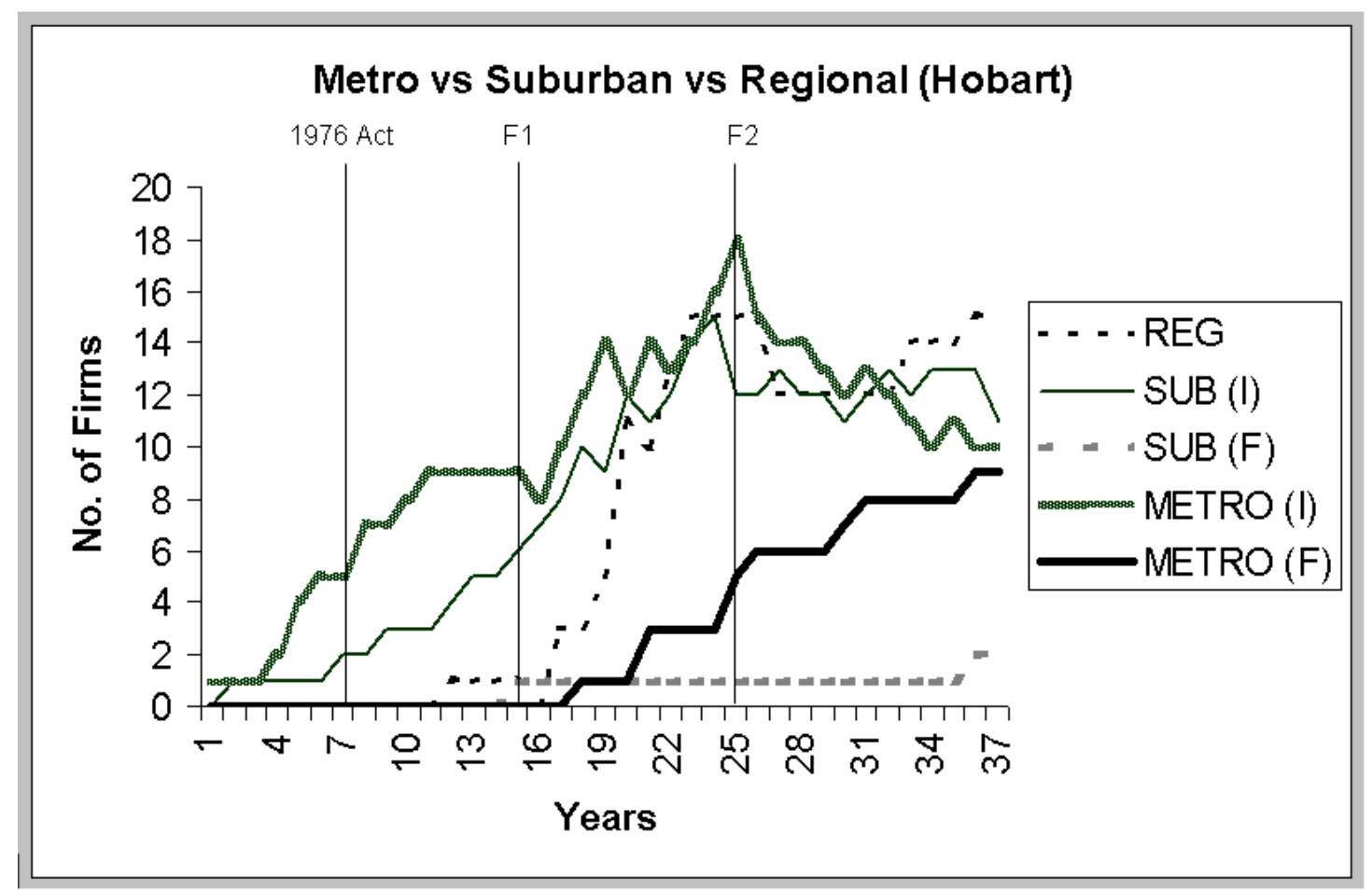

Within Figure 2, three distinct selective neighbourhoods are identified. They are, a metropolitan niche, a suburban niche, and a regional niche. There two types of operators shown, independents (I) and franchises (F). Initially, the metropolitan niche grew faster fuelled by the direct influence of increased nightclub patrons. Whilst it benefited from the arrival of $F 1$, the suburban niche also benefited more from the advent of home delivery. After the arrival of F1, we also observe the growth in the regional niche as the demand for pizza is transferred across all three niches through television advertising. The expansion of F1 to five outlets had a positive influence on all three niches. It is only with the arrival F2 that we observe the fallout from increased selection pressure. Most markedly within the metropolitan niche. It would appear that the kin selection afforded to the independents by F1 ceased with the arrival of F2.

It would also appear that F2 also indirectly impacted the regional niche temporally. As F1 shifted from the provider of prosperity to just another competitor, those metropolitan based independents expanded their boundaries to encroach further into the suburban niches. In a knock-on effect, the closest regional independents fought for resources with those suburban independents most under pressure from the independent metropolitan shops. Overtime, the regional niche has grown, as have the franchised firms in the metropolitan niche, at the expense of local independents in the metropolitan niche, and to a lesser extent the suburban niche. It would appear that as the 
home delivery of pizza has increased in popularity, the physical distance between the regional niche and the metropolitan niche has widened. Further, the continual use of television advertisements by the franchised operators has continued to transfer demand into the regional niches. This complex set of interrelated processes of selection and adaptation can be illustrated across Figures 3, 4, and 5.

In Figure 3, the suggested nature of the external, ecological, and selective environments is presented. The dominant feature is an abundance of resources through which population growth is possible. There is one, essentially homogeneous neighbourhood within which independent operators exist. High levels of networking were common for pioneers (e.g. social gatherings at the casino) and for most $1^{\text {st }}$ generation spin-offs (i.e. those first employed by the pioneers) who operated in a relatively non-competitive environment. Throughout this period, there is evidence of selection, but only weak directional selection acting against those unable to cope with the demands of increasing demand.

\section{Figure 3 - Period One}

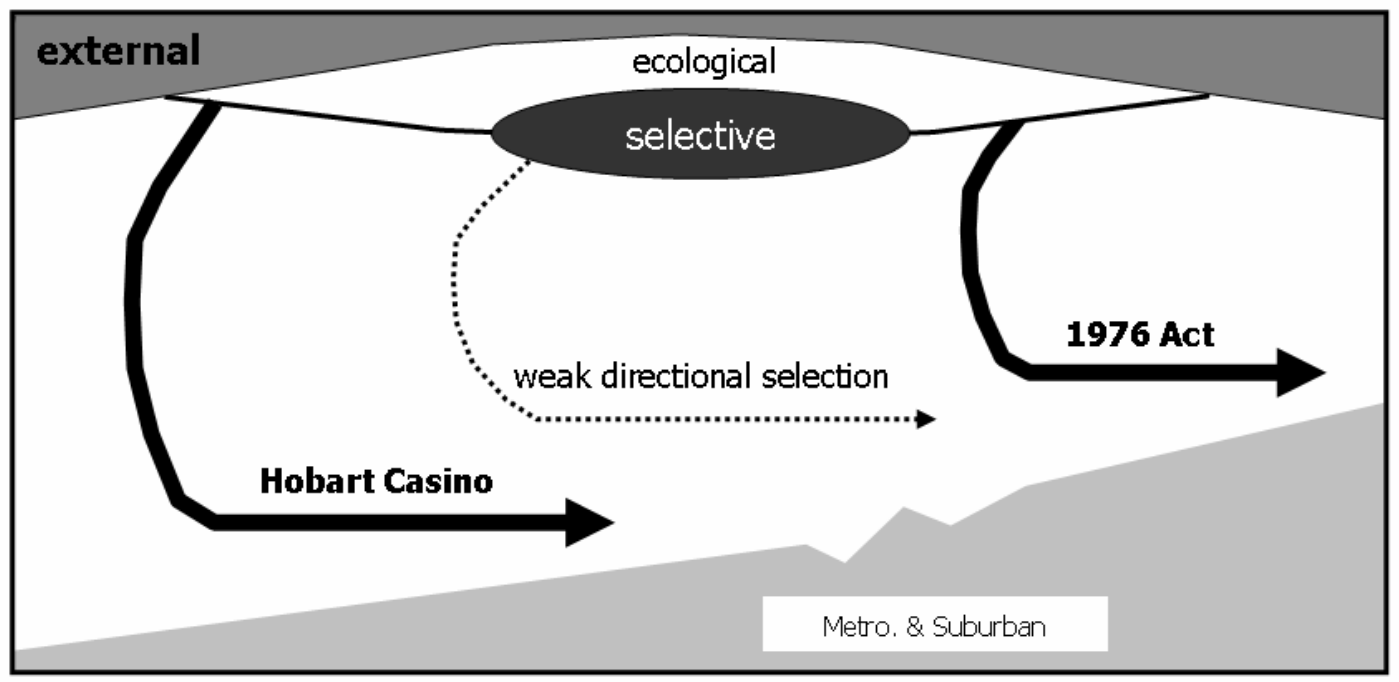

During period two, the nature and influence of the environment became more complex. As illustrated in Figure 4 below, kin selection is present, effectively deflecting the potential influence of any selection pressure. This kin selection is manifested through the presence of F1. Population growth is assisted by a 'buffer' directly related to the increased primary demand for pizza in specific metropolitan, suburban, and regional niches. Whilst each niche experienced different rates of growth, they all nevertheless experienced growth across period two. 
Figure 4 - Period Two

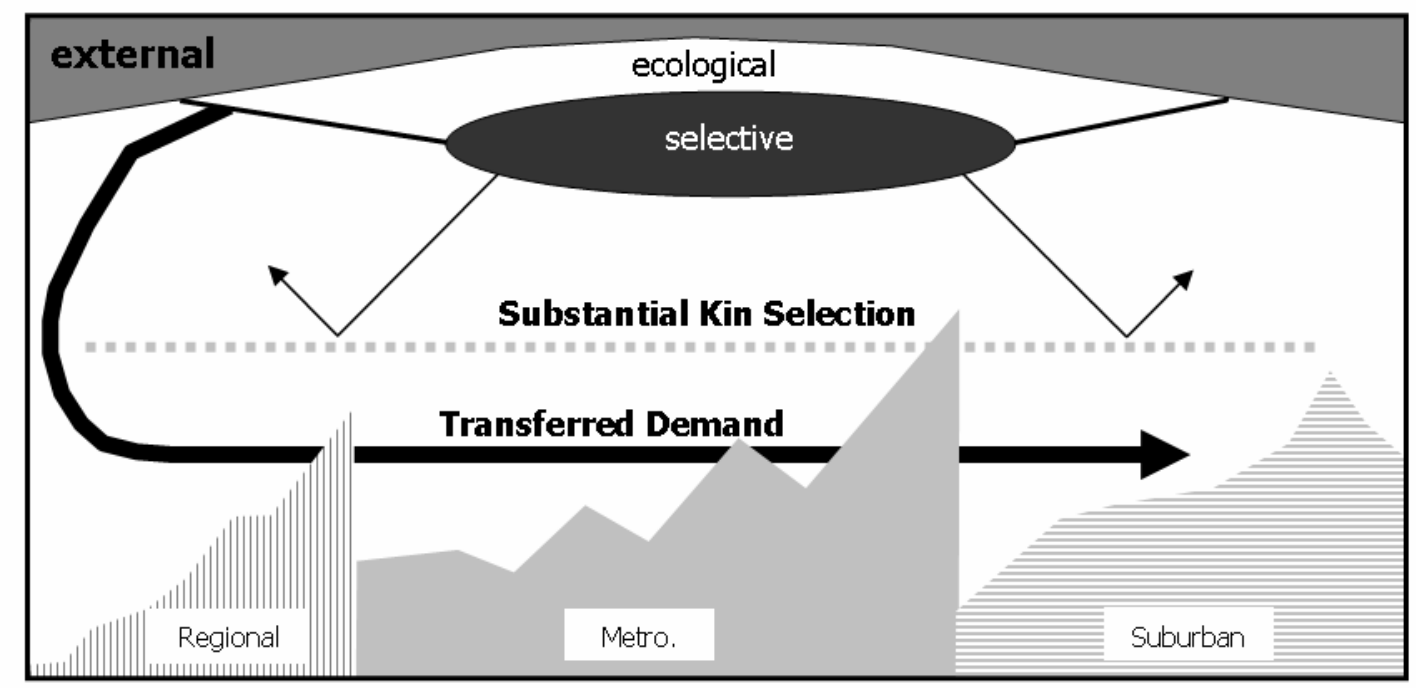

Figure 5 - Period Three

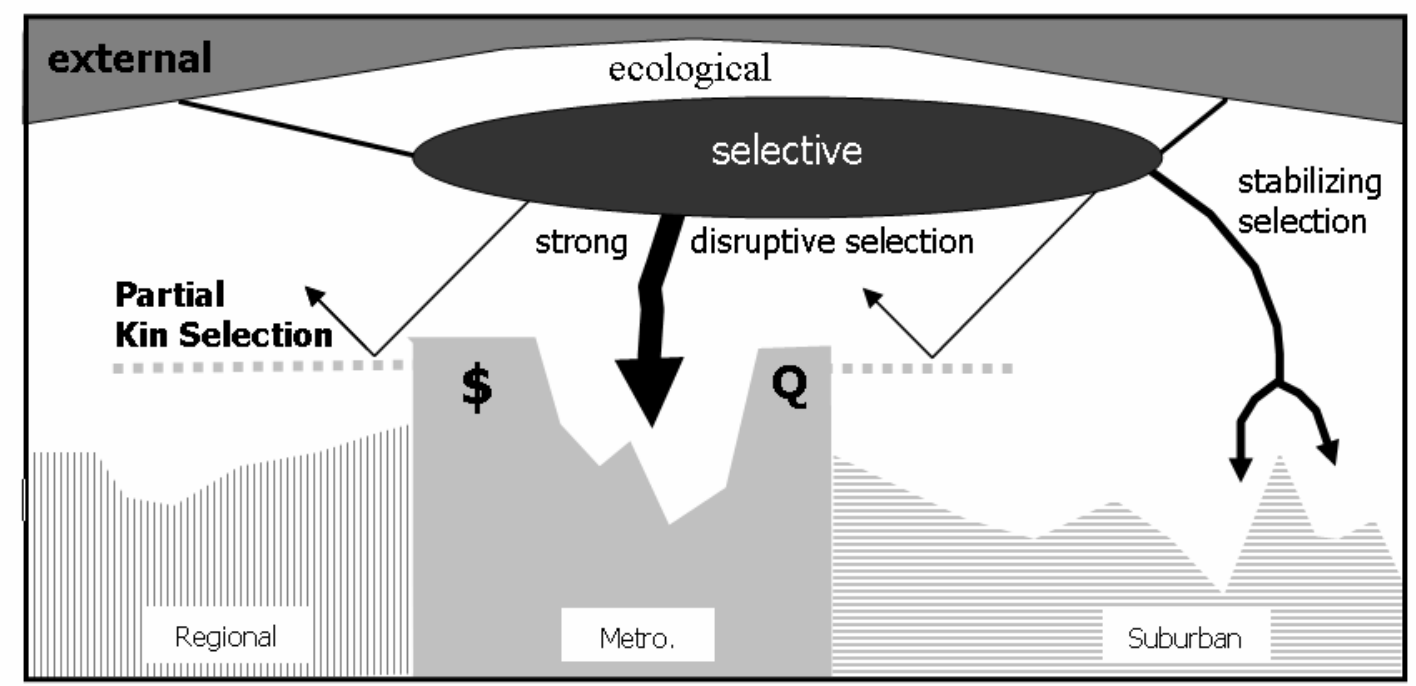

During period three (Figure 5), the complexity increased considerably. The entry of F2 is associated with the decreasing presence of kin selection within the metropolitan niche and a partial decrease in the suburban niche. It would seem that the geographical distance between the regional and metropolitan niches best explains the persistence of kin selection to regional operators. Whilst they still benefit from the mass advertising of the franchised operators, their operations are too far away to compete against any of the franchised operators. The outer lying suburban areas still benefit where their delivery zones fall beyond the preferred delivery zones of the metropolitan operators. Now, a strong form of disruptive selection pressure is operating on the metropolitan niche removing those firms that are neither positioned on quality nor operating as low-cost operators. Also, a stabilizing form of selection is 
seen to be occurring, selecting in favor of those firms with sufficient cashflows that are also well managed.

\section{Conclusion}

In summary, despite the preliminary nature of the findings discussed, sufficient evidence has so far emerged that it is necessary to go beyond previously used approaches to determine the nature of selection and adaptation related to population change. Failure to do so will leave investigators open to claims that reported outcomes are tautological. That is, that the better-adapted firms survive and the less adapted firms are selected against by the prevailing environmental forces. To date, no evidence has been found to support this traditional proposition. In fact, it would appear quite likely that further investigations might reveal quite the opposite. It would seem that many firms with perceived fitness have been selected against long before firms with an apparent lack of perceived fitness. The key determinate is the unevenness of selection pressure across time and space.

The critical issue to emerge so far is that the environment, the presence of selection, and the industry landscape are all slippery concepts that cannot simply be captured as static features of an industry across and within time. As has been claimed in other domains of study (Hoffmeister, Vet, Biere, Holsinger, and Filser, 2005), more work is urgently required to gain insights into how the modification and fragmentation of landscapes shape the evolutionary processes associated with population change. The failure to do so will prevent researchers from discovering causal explanations that explain how change occurs within a complex system involving mechanisms of variation, selection, and retention (or inheritance) (Hodgson, 2003).

The continual use of bookkeeping methods of enquiry may increasingly be subject to claims of being tautological in that they may not reveal the underlying causal processes through which change occurred. There is a need to explore beyond the application of evolutionary theory as currently applied to socio-economic evolution. This task is challenging, and Hodgson's (2001) plea for the principle of consistency to be observed is appropriate. The journey that lies ahead may not so much represent the exploration of new land with old knowledge. Rather, the necessary journey may initially be one of exploring our own understanding of how evolutionary theories have been developed in other areas of inquiry (e.g. ecology and biology).

In the spirit of Aldrich (1999), this paper seeks to highlight issues that deserve more attention. Issues that take centre place in other domains, but whose application is lacking in the area of organisational studies. In outlining a generic evolutionary framework for understanding social change, Aldrich urges the continual exploration of a research space that is still very incomplete. So, opportunities await those that wish to attempt the challenging, yet highly rewarding intellectual task of importing developed theory into our research space to help light the way forward. That we might start to see the environment as three distinct spaces will help to narrow our focus on those factors that aid growth and those that increase the intensity of selection. 
Likewise, an appreciation of the degree of heterogeneity within and across an industry alters significantly they way sense is made of why some firms have succeeded where others have failed.

In bringing in old ideas to help construct new explanations of organisational change, creditability is enhanced through adherence to the principle of consistency. Hodgson, (2001, p. 92) states "explanations in one domain have to be consistent with explanations in another, despite examination of different properties and deployment of different concepts". This simple, yet exacting principle requires that in many instances we must go backwards (in degrees of understanding) before we can advance. This however is the true challenge for any researcher serious about the development of an evolutionary account of organisational change driven by the identification of a set of underlying causal processes.

\section{References}

Aldrich, H.E. (1999), Organizations Evolving, Sage Publications, London.

Amburgey, T.L., Kelly, D. and Barnett, W.P. (1993), "Resetting the clock: The dynamics of organizational change", Administrative Science Quarterly, Vol. 38 No. 1, pp. 51-73.

Amburgey, T.L., Dacin, T. and Kelly, D. (1994), 'Disruptive selection and population segmentation: Interpopulation competition as a segregating process', in Baum, J.A.C. and Singh, J.V. (Eds.), Evolutionary Dynamics of Organizations, Oxford University Press, New York, pp. 240-254.

Amburgey, T.L., and Singh, J.V. (2002), 'Organizational evolution', in Baum, J.A.C. (Ed.), Companion to Organizations, Blackwell, Oxford, UK, pp. 327343.

Brandon, R.N. (1990), Adaptation and Environment, Princeton University Press, Princeton, NJ.

Bruderer, E. and Singh, J.T. (1996), "Organizational evolution, learning, and selection: A genetic-algorithm-based model", Academy of Management Journal, Vol. 39 No. 5, pp 1322-1349.

Darwin, C. (1901), The Origin of Species by Means of Natural Selection, J. Murray, London.

Evans, M.G., and Usher, J.M. (1996), "Life and death along gasoline alley: Darwinian and Lamarckian processes in a differentiating population," Academy of Management Journal, Vol. 39 No. 5, pp. 1428-1466.

Grant, V. (1985), The Evolutionary Process: A Critical Review of Evolutionary Theory, Columbia University Press, New York. 
Hannan, M.T. and Freeman, J. (1989), Organizational Ecology, Harvard University Press, Cambridge, MA.

Haveman, H.A. (1992), "Between a rock and a hard place: Organizational change and performance under conditions of fundamental environmental transformation", Administrative Science Quarterly, Vol. 37 No. 1, pp. 48-75.

Hodgson, G. M. (1993), Economics and Evolution: Bringing Life Back into Economics, Polity Press, Cambridge, UK.

Hodgson, G.M. (2001), 'Is social evolution Lamarckian or Darwinian', in Nightingale, J. and Laurent, J. (Eds.), Darwinism and Evolutionary Economics, Edward Elgar, Cheltenham, pp. 87-118.

Hodgson, G.M. (2003), "Darwinism and institutional economics", Journal of Economic Issues, Vol 37. No. 1, pp. 85-97.

Hoffmeister, T.S., Vet, L.E.M., Biere, A., Holsinger, K. and Filser, J. (2005) "Ecological and evolutionary consequences of biological invasion and habitat fragmentation", Ecosystems, Vol. 8, pp. 657-667.

Hull, D.L., Langman, R.E. and Glenn, S.S. (2001), 'A general account of selection', in Hull, D.L. (Ed.) Science and Selection, Cambridge University Press, New York, pp. 49-96.

Hull, D.L. (2001), Science and Selection, Cambridge University Press, Cambridge, MA.

Jones, C. (2005), "Firm transformation: Advancing a Darwinian perspective", Management Decision, Vol. 43 No 1, pp. 13-25.

Levinthal, D.A. (1991), "Organizational adaptation and environmental selection: Interrelated processes of change", Organization Science, Vol. 2 No 1, pp. 140-145.

Levitt, B. and March, J.G. (1988), 'Organizational learning', in Scott, W.R. and Blake, J. (Eds), Annual Review of Sociology, Vol 14, Annual Reviews, Palo Alto, CA, pp. 319-340.

Mayr, E. (1997), This is Biology: The Living Science of the Living World, Belknap Press, Cambridge, MA.

Nelson, R.R. and Winter, S.G. (1982), An Evolutionary Theory of Economic Change, Harvard University Press, Cambridge.

Tushman, M. L., and Romanelli, E. (1985), 'Organizational evolution: A metamorphosis model of convergence and reorientation', in Staw, B (Ed.) Research in Organizational Behaviour, Vol. 7, Jai Press, Greenwich: CA, pp. 171-222. 